Journal of Mathematics and Statistics 6 (3): 316-320, 2010

ISSN 1549-3644

(C) 2010 Science Publications

\title{
3-Unit System Comprising Two Types of Units with First Come First Served Repair Pattern Except When Both Types of Units are Waiting for Repair
}

\author{
${ }^{1}$ Amit Goyal, ${ }^{2}$ Gulshan Taneja and ${ }^{3}$ D.V. Singh \\ ${ }^{1}$ Depatment of Mathematics, G.G.G.I. Dinarpur, Ambala, Haryana, India \\ ${ }^{2}$ Depatment of Mathematics, M.D. University, Rohtak, Haryana, India \\ ${ }^{3}$ Depatment of Mathematics, N.I. Technology, Kurukshetra, Haryana, India
}

\begin{abstract}
Problem statement: In this study we investigated the probabilistic analysis of a three unit system working in a sugar Mill, wherein one unit is big and the other two units are small and identical, is examined. Upon failure of the big unit, both small units are made operative and failed unit is undertaken for repair immediately. Priority for operation is given to the big unit. Priority for repair is given to big unit if both types (i.e., big and small) of units are in queue to get the repair done. System is able to work with full capacity only if big unit or both small units are in good condition. If only one small unit is operable, the system works at reduced capacity. The system under consideration goes to rest during the non-seasonal period. Approach: System was analyzed by making use of semi-Markov processes and regenerative point technique and various measures of the system effectiveness are obtained including the profit incurred to the system. Results: Graphs had been plotted to depict the behavior of the profit with respect to failure rate for different values of repair rate and with respect to revenue per unit up time for which system is working at full capacity for different values of cost for PM/CM. Conclusion: The profit increases with the decrease in the values of the failure rate and with the increase in the values of revenue per unit up time. It has lower (higher) values on increasing the values of cost (repair rate). Cut-off points obtained for failure rate help decide about having the system with failure rate lesser than that the value at cut-off point. Also, the price of the product should be fixed in such a way so as to get the revenue greater than the value at cut-off point.
\end{abstract}

Key words: 3-unit system, two types of units, operating and rest periods, regenerative point technique, reliability, measure of system effectiveness, cost benefit analysis

\section{INTRODUCTION}

Two/three-unit standby systems with two stages, that is, working or failed, have been widely discussed under various assumptions/situations by a large number of researchers including (Mokaddis et al., 1997; Tuteja et al., 2001; Goel et al., 1986; Taneja and Nanda, 2003; Li et al., 1998; Dhillon, 1992; Taneja, 2005; Rizwan, 2007; Murari and Maruthachalam, 1981). There may be one more stage i.e., stage of Rest period of the system which also exists in case of some seasonal systems like system working in a sugar mill. Goyal et al. (2009) studied reliability and profit analysis of a two-unit standby system working in a sugar mill with operating and rest periods. Thereafter, Goyal et al. (2010) did reliability modeling and analysis of a sulphated juice pump system comprising three identical units with two types of working capacity and rest period on the basis of information gathered visiting some sugar mills in Haryana (India). It was observed that the systems used in the mills remain in the functional mode seasonally (i.e., November to April in the present study) and go to Rest in the non-seasonal period (i.e., May to October). When the Rest period is about to complete, the PM/CM is carried out to make the system ready for operation. They considered that the priority for repair as well as operation is given to the big unit. However, from the economic point of view, it may not be good all the times to give such priority.

Thus, the present study analyses the reliability and economic aspect of such a system considering FCFS (first come first served) pattern for repair in all the cases except when both types of units are waiting for repair. When different types of units (i.e., one big and one small) are waiting for repair, the priority for repair is given to big unit. It is also assumed on the basis of information obtained from the mills that the system is brought to study at reduced capacity when the system is about to go to the rest period due to shortage of sugarcane near the end of season. 


\section{MATERIALS AND METHODS}

In this study, the probabilistic analysis of the system is analyzed by making use of semi-Markov processes and regenerative point technique and have obtained various measures of system effectiveness such as Mean time to system failure, Availability at full capacity and reduced capacity, PM/CM analysis, busy period analysis of repairman during working and rest periods, Rest period analysis and profit function.

For other assumptions, (Goyal et al., 2010) may be referred to.

\section{Notations: \\ $\lambda_{1}$ : $\quad$ Constant failure rate of the big unit when \\ $\lambda_{2}$ : $\quad$ operative when operative \\ $\mathrm{g}_{1}(\mathrm{t}), \mathrm{G}_{1}(\mathrm{t}): \quad$ p.d.f. and c.d.f. of repair time for big unit during working period \\ $\mathrm{g}_{2}(\mathrm{t}), \mathrm{G}_{2}(\mathrm{t}): \quad$ p.d.f. and c.d.f. of repair time for big unit during rest period \\ $\mathrm{h}_{1}(\mathrm{t}), \mathrm{H}_{1}(\mathrm{t})$ : p.d.f. and c.d.f. of repair time for small unit during working period \\ $\mathrm{h}_{2}(\mathrm{t}), \mathrm{H}_{2}(\mathrm{t})$ : p.d.f. and c.d.f. of repair time for small unit during rest period \\ $\mathrm{q}_{\mathrm{ij}}(\mathrm{t}), \mathrm{Q}_{\mathrm{ij}}(\mathrm{t}): \quad$ p.d.f. and c.d.f. of first passage time from a regenerative state $\mathrm{i}$ to a regenerative state $\mathrm{j}$ or to a failed state $\mathrm{j}$ without visiting any other regenerative state in $(0, t]$ \\ $\Phi_{\mathrm{i}}(\mathrm{t}): \quad$ c.d.f. of first passage time from a regenerative state $i$ to a failed state $j$ \\ $\gamma: \quad$ Rate of going to rest \\ $\alpha_{1}$ : $\quad$ Rate of change from full capacity to reduced capacity \\ $\alpha_{2}$ : $\quad$ Rate of change from reduced capacity to full capacity \\ $\gamma_{1}, \gamma_{2}, \gamma_{3}, \gamma_{4}, \gamma_{5}$ : Rate when rest period is about to start \\ $\beta_{1}$ : $\quad$ Rate of going for PM/CM \\ $\beta_{2}$ : $\quad$ Rate of doing PM/CM \\ $\beta_{3}$ : $\quad$ Rate of starting of the working period after the completion of $\mathrm{PM} / \mathrm{CM}$}

\section{Symbols for the states of system:}

$\beta_{0}$ : $\quad$ Big unit is operative

$\mathrm{S}_{0}$ : $\quad$ Small unit is operative

$\mathrm{B}_{\mathrm{s}}$ : $\quad$ Big unit as cold standby

$\mathrm{S}_{\mathrm{s}}$ : $\quad$ Small unit as cold standby
$\mathrm{F}_{\mathrm{Br}}$ : Repair of big unit under repairman when failed

$\mathrm{S}_{\mathrm{r}}$ : $\quad$ Repair of small unit under repairman when failed

$\mathrm{F}_{\mathrm{Brr}}$ : Repair of big unit under repairman when failed in rest state

$\mathrm{S}_{\mathrm{rr}}$ : Repair of small unit under repairman when failed in rest state

$\mathrm{F}_{\text {Brus: }}$ Repair of big unit under suspension when failed

$\mathrm{S}_{\text {rus }}$ : Repair of small unit under suspension when failed

$\mathrm{F}_{\mathrm{BR}}$ : $\quad$ Big unit is under repair by repairman from previous state

$\mathrm{B}_{\mathrm{ro}}$ : Big unit ready to become operative as the working period is about to start

$\mathrm{S}_{\mathrm{rs}}$ : Small unit ready to become standby as the working period is about to start

$\mathrm{S}_{\mathrm{wr}}: \quad$ Small unit waiting for repair when failed

$\mathrm{r}_{\mathrm{B}}$ : $\quad$ Big unit under rest

$\mathrm{r}_{\mathrm{S}}$ : $\quad$ Small unit under rest

PM/CM: Preventive Maintenance

Maintenance/Corrective

The diagram showing the various states of transition of the system is shown in Fig. 1.

Transition probabilities and mean sojourn times: The epoch of entries into the states $0-11-20-25$ and 27 are regenerative points and thus these are regenerative states. States 9 and 19 are failed states. States 10, 11, $14,15,16,17,21,22$ and 23 are the states where the system is at rest. States 2, 4, 18 and 20 are states where rest period is about to start. States 5-8 and 21 are states where system is at reduced capacity.

The non-zero element $p_{i j}=s \rightarrow 0 q_{i j} *(s)$ is given by:

$\mathrm{p}_{01}=\frac{\lambda_{1}}{\lambda_{1}+\gamma_{1}} ; \mathrm{p}_{02}=\frac{\gamma_{1}}{\lambda_{1}+\gamma_{1}} ; \mathrm{p}_{01}=\mathrm{g}_{1} *\left(2 \lambda_{2}+\gamma_{2}\right)$

$\mathrm{p}_{13}=2 \lambda_{2} \frac{\left[1-\mathrm{g}_{1} *\left(2 \lambda_{2}+\gamma_{2}\right)\right.}{2 \lambda_{1}+\gamma_{2}}$

$\mathrm{p}_{13}=\gamma_{2} \frac{\left[1-\mathrm{g}_{1} *\left(2 \lambda_{2}+\gamma_{2}\right)\right.}{2 \lambda_{2}+\gamma_{2}}$

$\mathrm{p}_{14}=\gamma 2 \frac{\left[1-\mathrm{g}_{1} *\left(2 \lambda_{2}+\gamma_{2}\right)\right.}{2 \lambda_{2}+\gamma_{2}}$

$\mathrm{p}_{25}=\mathrm{p}_{36}=\mathrm{p}_{47}=\mathrm{p}_{5,15}=1 ; \mathrm{p}_{68}=\mathrm{g}_{1} *\left(\lambda_{2}+\gamma_{3}\right)$

$\mathrm{p}_{69}=\frac{\lambda_{2}+\gamma_{2}}{\gamma_{3}+\lambda_{2}}\left[1-\mathrm{g} 1 *\left(\lambda_{2}+\gamma_{3}\right)\right]=\mathrm{p}_{6,13}^{(9)}$

$\mathrm{p}_{69}^{(10)}=\frac{\gamma_{3}}{\gamma_{3}+\lambda_{2}}\left[1-\mathrm{g} 1 *\left(\lambda_{2}+\gamma_{3}\right)\right]=\mathrm{p}_{7,11}=1$ 


$$
\begin{aligned}
& \mathrm{P}_{8,12}=\mathrm{p}_{11,15}=\mathrm{p}_{14,15}=\mathrm{p}_{15,16}=\mathrm{p}_{16,17}=1 \\
& \mathrm{P}_{17,0}=1 ; \mathrm{p}_{12,0}=\mathrm{h}_{1}^{*}\left(\lambda_{1}+\gamma_{4}\right) \\
& \mathrm{p}_{12,24}=\frac{\lambda_{1}}{\gamma_{4}+\lambda_{1}}\left[1-\mathrm{h}_{1} *\left(\lambda_{1}+\gamma_{4}\right)\right] \\
& \mathrm{p}_{12,18}=\frac{\gamma_{4}}{\gamma_{4}+\lambda_{1}}\left[1-\mathrm{h}_{1} *\left(\lambda_{1}+\gamma_{4}\right)\right] \\
& \mathrm{p}_{13,12}=\mathrm{h}_{1} *\left(\lambda_{1}+\gamma_{5}\right) \\
& \mathrm{p}_{13,19}=\frac{\lambda_{1}}{\gamma_{5}+\lambda_{1}}\left[1-\mathrm{h}_{1} *\left(\lambda_{1}+\gamma_{5}\right)\right]=\mathrm{p}_{13,6}^{(19)}
\end{aligned}
$$$$
\mathrm{p}_{13,20}=\frac{\gamma_{5}}{\gamma_{5}+\lambda_{1}}\left[1-\mathrm{h}_{1} *\left(\lambda_{1}+\gamma_{5}\right)\right]
$$$$
\mathrm{p}_{8,21}=\mathrm{p}_{20,22}=\mathrm{p}_{21,23}=\mathrm{p}_{22,14}=\mathrm{p}_{23,15}=1
$$$$
\mathrm{p}_{24,25}=1
$$$$
\mathrm{p}_{25,1}=\mathrm{h}_{1} *\left(\lambda_{2}+\gamma_{5}\right)
$$$$
\mathrm{p}_{25,6}^{(19)}=\mathrm{P}_{25,19} \frac{\lambda_{2}}{\gamma_{5}+\lambda_{2}}\left[1-\mathrm{h}_{1} *\left(\lambda_{2}+\gamma_{5}\right)\right]
$$$$
\mathrm{p}_{25,27}^{(26)}=\frac{\gamma_{5}}{\gamma_{5}+\lambda_{2}}\left[1-\mathrm{h}_{1} *\left(\lambda_{2}+\gamma_{5}\right)\right]=\mathrm{p}_{25,15}=1
$$

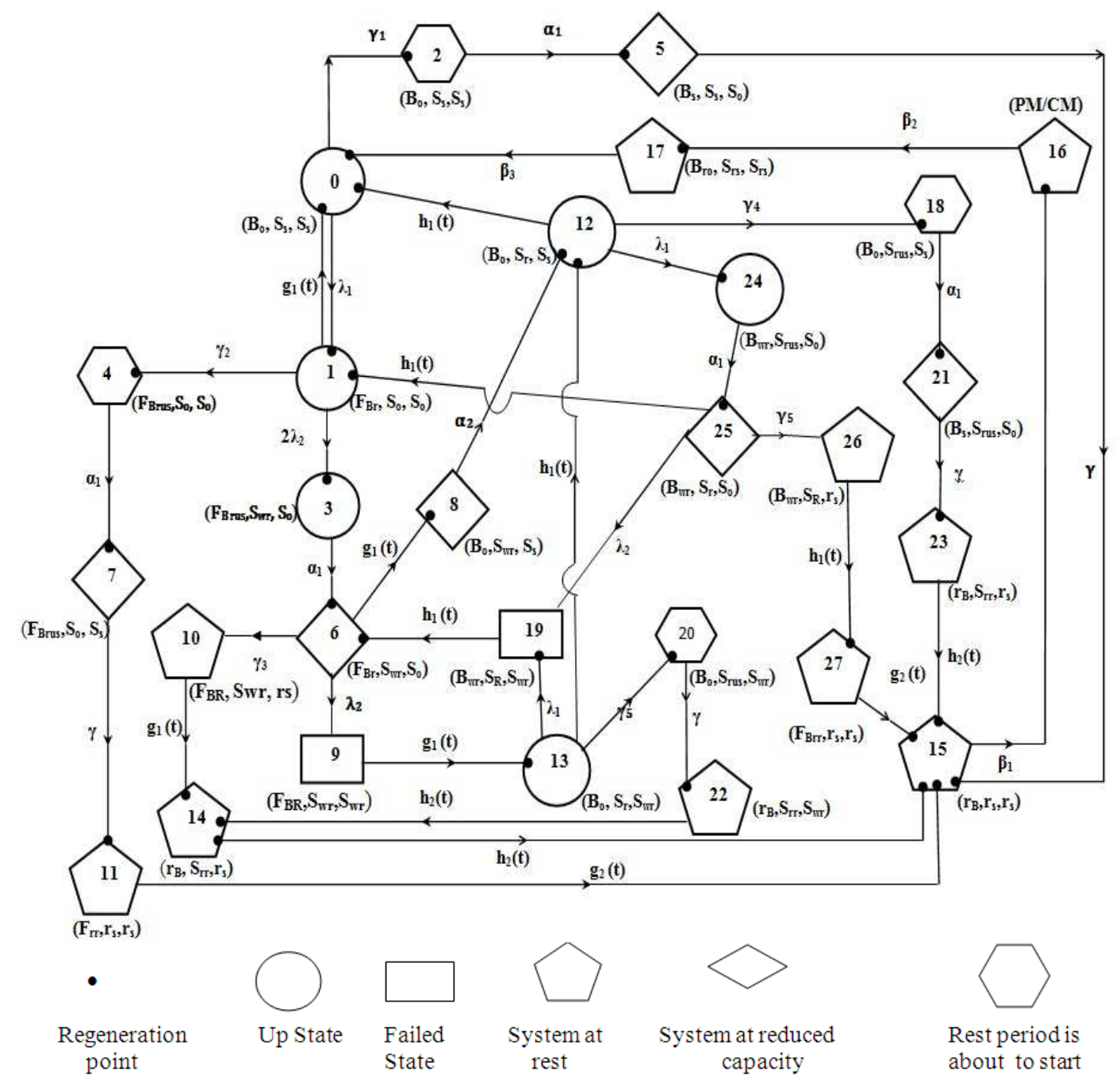

Fig. 1: State transition diagram

Mean Sojourn times $\left(\mu_{\mathrm{i}}\right)$ in the regenerative state ' $i$ ' is defined as the time of stay in that state before transition to any other state. If $\mathrm{T}$ denotes the sojourn time in the regenerative state $i$, then:

$$
\mu_{\mathrm{i}}=\mathrm{E}(\mathrm{T})=\operatorname{Pr}(\mathrm{T}>\mathrm{y})
$$

The unconditional mean time taken by the system to transit for any regenerative state $\mathrm{j}$, when it is counted 
from the epoch of entrance in to the state $i$, is mathematically stated as:

$$
\mathrm{m}_{\mathrm{ij}}=\int_{0}^{\infty} \operatorname{tdQ}_{\mathrm{ij}}(\mathrm{t})=-\mathrm{q}_{\mathrm{ij}}^{*}(0)
$$

Measures of the system effectiveness: Following measures of the system effectiveness are obtained using semi-Markov processes, regenerative point technique, recursive relations and Laplace/Stieltjes' transforms:

- Mean time to system failure (Including rest period)

- Steady state availability at full capacity $\left(\mathrm{A}_{0}\right)$

- Availability Analysis at Reduced Capacity $\left(\mathrm{AR}_{0}\right)$

- Analysis of the expected rest period of the system $\left(\mathrm{R}_{0}\right)$

- Busy period analysis for repairing the failed units during working period for Big Unit $\left(\mathrm{B}_{0}\right)$

- $\quad$ Busy period analysis for repairing the failed units during working period for Small Unit $\left(\mathrm{BS}_{0}\right)$

- Busy period analysis for repairing the failed units during rest period for Big Unit $\left(\mathrm{BR}_{0}\right)$

- Busy period analysis for repairing the failed units during rest period for Small Unit $\left(\mathrm{BRS}_{0}\right)$

- $\mathrm{PM} / \mathrm{CM}$ Analysis of the system

Cost-benefit analysis: In steady state, the expected profit per unit time incurred to the system is given by:

$\begin{aligned} \text { Profit }\left(\mathrm{P}_{2}\right)= & \mathrm{C}_{0} \mathrm{~A}_{0}+\mathrm{C}_{1} \mathrm{AR}_{0}-\mathrm{C}_{2} \mathrm{~B}_{0}-\mathrm{C}_{3} \mathrm{BS}_{0}-\mathrm{C}_{4} \mathrm{P}_{0}-\mathrm{C}_{5} \mathrm{BR}_{0} \\ & -\mathrm{C}_{6} \mathrm{BRS}_{0}-\mathrm{C} \mathrm{R}_{0}\end{aligned}$

Where:

$\mathrm{C}_{0}=$ Revenue per unit up time for which system is working at full capacity

$\mathrm{C}_{1}=$ Revenue per unit up time for which system is working at reduced capacity

$\mathrm{C}_{2}=$ Cost per unit time for which the repairman is busy to repair big unit

$\mathrm{C}_{3}=$ Cost per unit time for which the repairman is busy to repair small unit

$\mathrm{C}_{4}=$ Cost per unit time for PM/CM

$\mathrm{C}_{5}=$ Cost per unit time for which the repairman is busy to repair big unit at rest period

$\mathrm{C}_{6}=$ Cost per unit time for which the repairman is busy to repair small unit at rest period

$\mathrm{C}_{7}=$ Cost per unit time for which the system remains at rest

\section{RESULTS}

The following particular case is considered to obtain various results:

$$
g_{1}(t)=\alpha e^{-\alpha t} ; g_{2}(t)=\beta e^{-\beta t} ; h_{1}(t)=\lambda^{e-\lambda t} ; h_{2}(t)=\mu^{e-\mu t}
$$

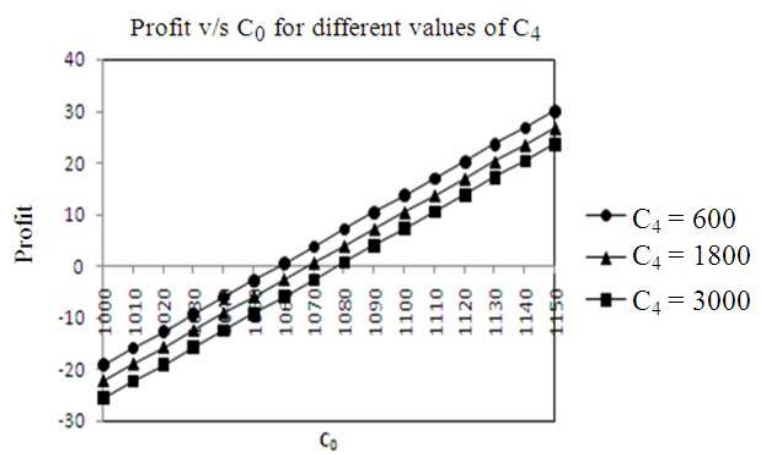

Fig. 2: Profit versus revenue per unit up time for different values of cost per unit time for $\mathrm{PM} / \mathrm{CM}$

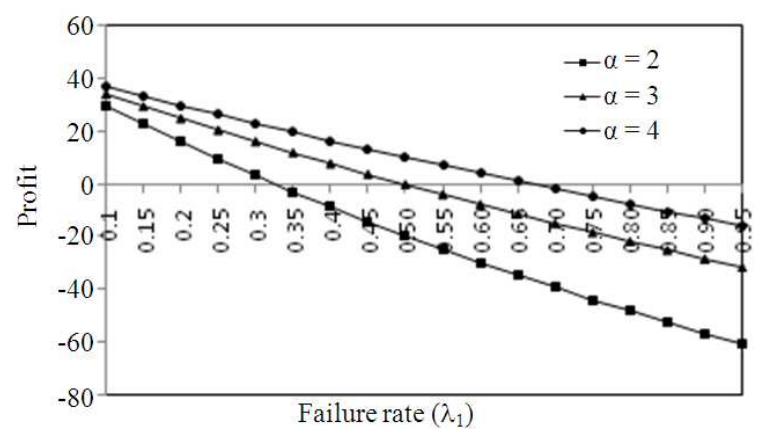

Fig. 3: Profit versus failure rate $\left(\lambda_{1}\right)$ for different values of repair rate $(\alpha)$

For taking the values of $\beta_{1}=0.002 ; \beta_{2}=0.25 ; \beta_{3}=$ $100 ; \beta=0.25 ; \gamma=\gamma_{1}=\gamma_{2}=\gamma_{3}=\gamma_{4}=\gamma_{5}=0.002 ; \alpha_{1}=\alpha_{2}=$ $100 ; \mathrm{C}_{1}=500 ; \mathrm{C}_{2}=800 ; \mathrm{C}_{3}=400 ; \mathrm{C}_{5}=800 ; \mathrm{C}_{6}=1000 ;$ $\mathrm{C}_{7}=1350$ the graph for profit with respect to failure rate for different values of repair rate is plotted in Fig. 2 .

Taking the values $\beta_{1}=0.002 ; \beta_{2}=0.25 ; \beta_{3}=100 ; \beta$ $=0.25 ; \gamma=\gamma_{1}=\gamma_{2}=\gamma_{3}=\gamma_{4}=\gamma_{5}=0.002 ; \alpha_{1}=\alpha_{2}=100$; $\mathrm{C}_{0}=1000 ; \mathrm{C}_{1}=500 ; \mathrm{C}_{2}=800 ; \mathrm{C}_{3}=400 ; \mathrm{C}_{4}=\mathrm{C}_{5}=800$; $C_{6}=1000 ; C_{7}=1350$ the graph for profit with respect to failure rate for different values of repair rate is plotted in Fig. 3.

\section{DISCUSSION}

Figure 2 depicts that the profit increases with the increase in the values of $\mathrm{C}_{0}$. But $\mathrm{C}_{0}$ has the lower values on increasing the values of $\mathrm{C}_{4}$. The following can also be interpreted from Fig. 2:

- For $\mathrm{C}_{4}=600$, the value of the profit is $>$ or $=$ or $<0$ according to whether $\mathrm{C}_{0}>$ or $=$ or $<1058.51$. So, in this case the system is profitable only if $\mathrm{C}_{0}>058.51$ 
- For $_{4}=1800$, the value of the profit is $>$ or $=$ or $<0$ according to whether $\mathrm{C}_{0}>$ or $=$ or $<1068.30$. So, in this case the system is profitable only if $\mathrm{C}_{0}>1068.30$

- For $\mathrm{C}_{4}=3000$, the value of the profit is $>$ or $=$ or $<0$ according to whether $\mathrm{C}_{0}>$ or $=$ or $<1078.10$. So, in this case the system is profitable only if $\mathrm{C}_{0}>078.10$

Figure 3 depicts that the profit decreases with the increase in the values of $\lambda_{1}$. But $\lambda_{1}$ has the higher values on increasing the values of $\alpha$. The following can also be interpreted from Fig. 3:

- For $\alpha=2$, the value of the profit is $>$ or $=$ or $<0$ according to whether the failure rate $\left(\lambda_{1}\right)$ is <or $=$ or $>0.3248$. So, in this case the system is profitable only if the $\lambda_{1}<0.3248$

- For $\alpha=3$, the value of the profit is $>$ or $=$ or $<0$ according to whether the failure rate $\left(\lambda_{1}\right)$ is $<$ or $=$ or $>0.4962$. So, in this case the system is profitable only if the $\lambda_{1}<0.4962$

- For $\alpha=4$, the value of the profit is $>$ or $=$ or $<0$ according to whether the failure rate $\left(\lambda_{1}\right)$ is <or $=$ or $>0.6661$. So, in this case the system is profitable only if the $\lambda_{1}<0.6661$

\section{CONCLUSION}

It is concluded that the cut-off points for failure rate can be obtained which help decide that that system should be had/purchased which has the failure rate lesser than the value at cut-off point.

Also, the cut-off point for the revenue per unit up time reveals that the price for the product being manufactured by the user of the system should be fixed in such a way that the revenue per unit up time comes out to be greater than the value at cut-off point so that a positive profit is attained.

Recommendation/suggestion for the users of such system: The user of such system should adopt the model discussed and implement it for deciding about fixing of various costs like payment made to the repairman, the sales prices of the product and maximum acceptable failure rate of the system.

\section{REFERENCES}

Dhillon, B.S., 1992. Stochastic modeling of k-out-of-n units family of system. Int. J. Syst. Sci., 23: $\quad 1277-1287 . \quad$ DOI: $10.1080 / 00207729208949382$
Goel, L.R., G.C. Sharma and P. Gupta, 1986. Reliability analysis of a system with preventive maintenance inspection and two type of repair. Microelect. Reliab., 26: 429-433. http://cat.inist.fr/?aModele $=$ afficheN\&cpsidt=7912 618

Goyal, A., G. Taneja and D.V. Singh, 2009. Reliability and profit evaluation of a 2-unit cold standby system working in a sugar mill with operating and rest periods. Caledon. J. Eng. Oman, 5: 1-5.

Goyal, A., G. Taneja and D.V. Singh, 2010. Reliability modeling and analysis of a sulphated juice pump system comprising three identical units with two types of working capacity and rest period. Pure Applied Math. Sci., 71: 133-143.

Li, W., A.S. Alfa and Y.Q. Zhao, 1998. Stochastic analysis of a repairable system with three units and repair facilities. Microelect. Reliab., 38: 585-595. DOI: 10.1016/S0026-2714(97)00204-7

Murari, K. and C. Maruthachalam, 1981. Two-unit parallel system with periods of working and rest. IEEE Trans. Reliab., 30: 91-91. DOI: 10.1109/TR.1981.5220984

Mokaddis, G.S., S.W. Labib and A.M. Ahmed, 1997. Analysis of a two-unit warm standby system subject to degradation. Microelect. Reliab., 37: 641-648. DOI: 10.1016/S0026-2714(96)00070-4

Rizwan, S.M., 2007. Reliability analysis of a two unit system with two repairmen. Caledon. J. Eng. Oman, 3: 1-5

Taneja, G. and J. Nanda, 2003. Probabilistic analysis of a two-unit cold standby system with resume and repeat repair polices. Pure Applied Math. Sci., 57: 37-50.

http://direct.bl.uk/bld/PlaceOrder.do?UIN=136059 $902 \&$ ETOC $=$ RN $\&$ from $=$ searchengine

Taneja, G., 2005. Reliability and profit analysis of a system with PLC used as hot standby. Proceeding of International Conference on Reliability and system Engineering, Dec. 21-23, Reliability Engineering Centre, Kharagpur, India, pp: 455-464.

Tuteja, R.K., G. Taneja and A. Malik, 2001. Reliability and profit analysis of two-unit cold standby system with partial failure and two types of repairman. J. Dec. Math. Sci., 5-6: 59-74. 